\title{
Tradição do Fazer Louças Cerâmicas: o design da informação na construção gráfica da cadeia produtiva artesanal
}

\author{
Tradition of Making Ceramic Tableware: information design in the graphic \\ construction of the artisanal production chain
}

\author{
Samuel da Silva Miranda, Denilson Moreira Santos, Ferdinan Silva de Sousa, \\ Elinaldo de Jesus Mendes
}

cadeia produtiva, anas das louças, tradicional, comunicar

O propósito deste artigo é relatar a sistematização e construção gráfica da cadeia produtiva de louças cerâmicas, produzidas tradicionalmente por um grupo de cinco artesãs, chamadas de Anas das Louças. Essas mulheres quilombolas, produzem suas peças, carregadas de conhecimento tradicional, situadas no povoado de Porto dos Nascimentos, pertencente ao município maranhense de Mirinzal - MA. A abordagem deste escrito, traz resultados de pesquisa da dissertação de mestrado que objetivou analisar a prática tradicional das artesãs com os conhecimentos especializados do design, com foco nas avaliações dos materiais empregados e suas caracterizações. A dissertação mostra em sua primeira fase metodológica, as nuances da cadeia produtiva e a característica que difere as louças das Anas de outras louças tradicionais em cerâmica da região - o uso do recurso vegetal chamado de Taquipé (Triplaris. Sp). Especificamente, utiliza-se as cinzas da casca de uma árvore homônima, que são incorporadas à argila vermelha para a produção das peças. Logo, este artigo traz um relato de experiência de pesquisa, priorizando o resultado da construção e organização das informações da cadeia produtiva, por meio de elaboração gráfica, com o intento de comunicar informações de forma criativa e estruturada acerca do percurso produtivo tradicional dos artefatos.

productive chain, anas crockery, traditional, communicate

The purpose of this article is to report on the systematization and graphic construction of the ceramic chinaware production chain, traditionally produced by a group of five artisans, called Anas das Louças. These quilombola women produce their pieces, loaded with traditional knowledge, located in the village of Porto dos Nascimentos, belonging to the municipality of Mirinzal - MA, Maranhão. The approach of this writing brings research results from the master's thesis that aimed to analyze the traditional practice of artisans with the specialized knowledge of design, focusing on the evaluation of the materials used and their characterizations. The dissertation shows, in its first methodological phase, the nuances of the production chain and the characteristic that distinguishes Anas dishes from other traditional ceramic dishes in the region - the use of the vegetable resource called Taquipé (Triplaris. Sp). Specifically, the ashes of the bark of a homonymous tree are used, which are incorporated into the red clay for the production of the pieces. Therefore, this article brings an account of research experience, prioritizing the result of the construction and organization of information in the production chain, through graphic elaboration, with the intent of communicating information in a creative and structured way about the traditional production path of the artifacts.

Anais do $10^{\circ} \mathrm{CIDI}$ e $10^{\circ} \mathrm{CONGIC}$

Kelli C.A.S. Smythe, Rafael de Castro Andrade (orgs.)

Sociedade Brasileira de Design da Informação - SBDI

Curitiba | Brasil | 2021
Proceedings of the $10^{\text {th }} \mathrm{CIDI}$ and $10^{\text {th }}$ CONGIC

Kelli C.A.S. Smythe, Rafael de Castro Andrade (orgs.)

Sociedade Brasileira de Design da Informação - SBDI Curitiba | Brazil | 2021 


\section{Introdução}

Realizar pesquisa de campo é quase sempre um relato sobre uma viagem, por onde o sujeito busca encontrar pessoas e lugares, já visitados ou não. Essa constatação não é inovadora, mas, configura-se como uma diferente maneira para a observação e reflexão de um determinado contexto, envolvido nos estudos, de acordo com as experiências apreendidas e as realidades intrínsecas dos territórios (DUARTE, 2002). Considerar o campo nas pesquisas em design, resulta no caminho de grande potencial dialógico, imersivo e de atenção, efetivando análises por meio de aproximações e/ou mediações com o meio.

No design, como aborda Noronha et. al (2017), a atividade que pretende apreender e traduzir informações, por meio das experiências em campo, tem sido primordial, principalmente para aqueles que se relacionam efetivamente com o território. Mas, cabe observar que as relações entre designers e os outros atores do campo devem considerar a problematização dessa relação, sobretudo nos aspectos socioculturais.

Percebe-se um enfoque crescente, relacionado a pesquisas de design que objetivam favorecer a troca de saberes, entre conhecedores especializados (designers) e difusos (artesãos), como considera Manzini (2015). Nesta mesma obra o autor reflete sobre a ação contemporânea do ator especializado, configurado inicialmente pela sua atividade de intervenção, que deve ser capaz de multar para o acionamento da mediação de processos, sobretudo considerando a inserção e envolvimento dos designers difusos (atores sociais não especializados) nas correlações.

O engajamento dos detentores de conhecimentos múltiplos é abordado por Patrocínio (2015), relacionando as visões entre Victor Papanek e Gui Bonsiepe. Em sua leitura fica claro as ponderações a respeito dos níveis hierárquicos presentes nas relações do design, em que o modelo conceitual - Escala Virtuosa do Design e do Desenvolvimento - considera os níveis do "Design Para, Design Em, Design Com e Design Por" que são degraus, ou estágios de atuação do design, objetivando, a cada novo passo, a autonomia dos detentores de conhecimento tácito, sem a interferência de atores sociais especializados.

Corrobora-se, portanto, com o pensamento crítico e necessário sobre a urgência da mutação nas ações do designer, promovendo um percurso que vá ao encontro da mediação e proposição de soluções de forma aberta e compartilhada com o contexto. É com esta concepção que a pesquisa desenvolvida em nível de mestrado acadêmico, pelo Programa de Pós-Graduação em Design da Universidade Federal do Maranhão, intitulada - A Tradição do Punhado: avaliação da incorporação da cinza de taquipé (Triplaris sp.) em argila vermelha na produção artesanal - lugar onde se recorta este artigo, se firmou, envolvendo os saberes e fazeres tradicionais com os especializados do campo do design (MIRANDA, 2020).

Para fim de contextualização, a pesquisa citada, objetivou avaliar a incorporação da cinza de taquipé em argila vermelha, por meio dos estudos em design e materiais, afim da comprovação dos fatores positivos relativos ao uso do compósito, desenvolvido pelo saberfazer das Anas das Louças. Mulheres quilombolas e artesãs que resistem, por meio da sua produção de louças cerâmicas a mais de duzentos anos. 
A principal característica das louças das Anas consiste principalmente pela incorporação de um recurso vegetal à argila vermelha da região. O taquipé, resultado da queima da casca de árvore homônima, que após processo de beneficiamento é misturado na argila para a produção das peças. Portanto, a cadeia produtiva das louças, consiste no processo do taquipé, inserido no processo das louças.

Por conseguinte, o objetivo deste artigo, consiste em comunicar a cadeia produtiva das louças cerâmicas, produzidas pelas Anas, sendo esta cadeia produtiva um dos resultados de pesquisa em mestrado acadêmico. Logo, busca-se apresentar o processo produtivo e criativo do desenvolvimento de uma peça gráfica, envolvendo as concepções do design da informação.

O resultado que apresenta-se, deriva em uma peça gráfica que exibe de forma objetiva e clara o processo produtivo dos artefatos, além de transparecer a tradição artesanal do fazer cerâmica, por meio de instrumentos auxiliares para este fim. Primeiramente, busca-se posicionar e diferenciar as pesquisas e tornar objetivo os percursos reflexivos propostos.

\section{Refletindo sobre a metodologia}

Este artigo traz resultados de pesquisa em nível de mestrado acadêmico. Cabe, portanto, explanar sobre o processo metodológico em que a pesquisa dissertativa se aleita e assim posicionar metodologicamente o recorte que pretende-se comunicar neste escrito.

A pesquisa de mestrado envolveu duas fases metodológicas. A primeira objetivou analisar a cadeia produtiva das louças, por meio da efetivação de observações em campo e dos diálogos, concretizados em meio aos fazeres. A segunda fase, primou pelo estudo avaliativo dos materiais, através da sua caracterização e dos ensaios referentes às propriedades tecnológicas. Os resultados da segunda fase não abrangem as ponderações objetivadas neste artigo. Toda essa abordagem metodológica foi adaptada na busca pela participação ativa de ambos os saberes e fazeres, especializados e difusos (MANZINI, 2015), como abordado na contextualização.

Apresenta-se neste artigo, de forma inédita, um recorte referente à primeira fase da pesquisa - Pesquisa de Campo - que buscou observar, por meio da observação sistemática, e compreender, pelo processo dialógico, sobre a cadeia produtiva das louças cerâmicas, produzidas pelas Anas. Entende-se Cadeia Produtiva na perspectiva de Krucken (2009), ao considerar esse processo como uma ligação de procedimentos, fases ou etapas, atores ou agentes e suas técnicas, envolvidos em algum fazer que resulta em produto, concebido desde de a chamada pré-produção até a destinação final (consumo).

O recorte consiste em comunicar, através dos artifícios e suportes desenvolvidos por ferramentas gráficas do design e na perspectiva do design da informação, a prática tradicional do fazer louças cerâmicas, pelas mãos de artesãs quilombolas, resultando em uma peça gráfica que apresenta todo o percurso das louças.

A importância de informar por meio do suporte gráfico, é refletida por Oliveira e Jorente (2015) ao apresentar uma revisão da literatura sobre o tema, onde os autores expõem que o 
Design da Informação, possui o objetivo de comunicar de forma eficiente a informação, assumindo a responsabilidade de apresentar corretamente o conteúdo e procurar objetividade no que se quer comunicar.

Como elemento inserido no Design da Informação, a linguagem apresenta fundamental importância para o desenvolvimento de artefatos gráficos. Sobre a linguagem Carvalho e Aragão (2012), refletem que ela se configura com um veículo que pretende comunicar de forma auditiva, sendo verbal ou não verbal, e visual, sendo gráfica ou não gráfica. Considerando a linguagem gráfica, a representação se dá de forma verbal, pictórica e/ou esquemática.

Neste sentido, outro elemento primordial na construção do artefato gráfico, considerando o Design da Informação é a iconografia e o uso de fotografias que formaram a base para o desenvolvimento e concepção dos resultados. Por iconografias admite-se neste artigo o conceito apresentado por Noronha et al. (2009, p. 6), que consiste na compreensão do "processo de identificação, descrição, classificação e interpretação dos significados simbólicos dos fazeres, saberes e histórias de determinado grupo ou cultura".

Os autores concluem que iconografar, compreende a ação de tangibilizar graficamente elementos imagéticos ou algo que ainda não foi graficamente interpretado, reunidos em signos e códigos pictóricos, sendo este caminho um importante meio de registro.

A cor corresponde a outro elemento fundamental na elaboração de artefatos gráficos com a concepção do design da informação. Corrobora-se com Tufte (2011), ao afirmar que a cor é utilizada para a aplicação de quatro características, rotular ou legendar, quando a cor assume um papel substantivo, medir, dando a ideia de quantidade, representar/imitar a realidade, na função da representação e a cor para animar ou decorar, quando o objetivo é usar a cor como beleza.

Almeja comunicar a cadeia produtiva, artesanal e tradicional, de louças cerâmicas, facilitando a transmissão da mensagem por meio da admissão de elementos que facilitem a interpretação das informações. Para isso, utilizou-se a linguagem gráfica, por meio do desenvolvimento e aplicação de iconografias, e aplicação da cor na função de representação, além da boa dinâmica e composição das imagens, junto a elementos gráficos como linhas, contornos e texturas.

Portanto, a conexão da abordagem com o design da informação se faz, para tornar legível esse processo criativo e produtivo tradicional, através de um artefato gráfico. Logo, para fim de compreensão dos resultados do processo gráfico, faz-se necessário apreender a respeito do fazer tradicional no qual envolveu-se, no caso, o fazer cerâmica pelas Anas das louças.

\section{O fazer tradicional das Anas das Louças}

O fazer tradicional que comunica-se neste artigo, corresponde ao artesanato em cerâmica do estado do Maranhão, especificamente da região da baixada maranhense, no povoado Porto do Nascimento, localidade próxima ao município de Mirinzal que por sua vez fica a $198 \mathrm{~km}$ da capital São Luís - MA. 
A região onde o município é situado localiza-se na Mesorregião do Norte Maranhense e na Microrregião do Litoral Ocidental Maranhense, centrada na faixa Norte do estado do Maranhão, pertencente ao sistema costeiro-marinho e ao bioma amazônico (IBGE, 2020). Na região ocorre a incidência do clima tropical úmido, sendo as fases de chuva e estiagem importantes para a garantia de parte da matéria-prima, utilizada na produção cerâmica.

Neste lugar, residem as Anas das Louças que são assim chamadas por formarem um grupo composto por cinco mulheres da mesma família, todas chamadas Ana. São elas a Ana Amélia, Ana Domingas, Ana das Graças, Ana Raimunda e Ana Alice (Figura 01).

Figura 01 - Anas das Louças
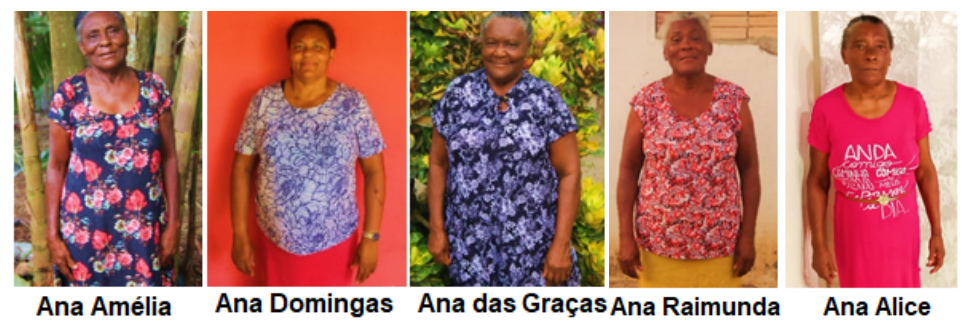

As Anas das Louças produzem suas peças pautadas no uso dos materiais que a natureza Ihes oferece. As artesãs empregam em constituição à argila vermelha um recurso vegetal denominado cinza de taquipé. Esta cinza resulta da queima das cascas de árvore de mesmo nome, encontrada na região de Porto dos Nascimentos (MIRANDA, 2020). Essa prática da inserção da cinza do taquipé em argila vermelha é tradicional no fazer das artesãs.

A ancestralidade é fortemente presente em meio a cada peça que sai das mãos das Anas, pois cada uma possui a herança histórica da forte presença ancestral dos povos negros da região, caracterizado pela existência de um dos maiores quilombos remanescentes no Brasil, o conhecido "quilombo Frechal" (FIGUEIREDO, 2009).

O quilombo Frechal é uma Unidade de Conservação ${ }^{1}$ que agrega a prática do cultivo e manejo tradicionais, através da conservação dos recursos provenientes do ambiente de forma compartilhada (BERNARDES \& MOTTA \& BOTELHO; 2011).

A produção desenvolvida pelas Anas das louças compreende na elaboração de panelas, frigideiras, tigelas, alguidares e outras louças (Figura 02), feitas a partir de modelagem manual em sua totalidade, com auxílio de outros elementos provenientes da natureza, tais como o anajá $^{2}$ e a cuipéua ${ }^{3}$ e artefatos domésticos tais como talheres e outros objetos, utilizados na fase de acabamento das peças (NORONHA, et al., 2017).

\footnotetext{
${ }^{1}$ A Lei no 9.985/2000 que regulamenta as Unidades de Conservação define estas como: "espaço territorial e seus

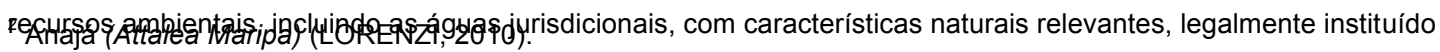

${ }^{3}$ Caco de cuia, proveniente de cabaça (Lagenaria vulgaris Ser) (GUIMARÃES et al., 2016)
} 
Figura 02 - As louças das Anas

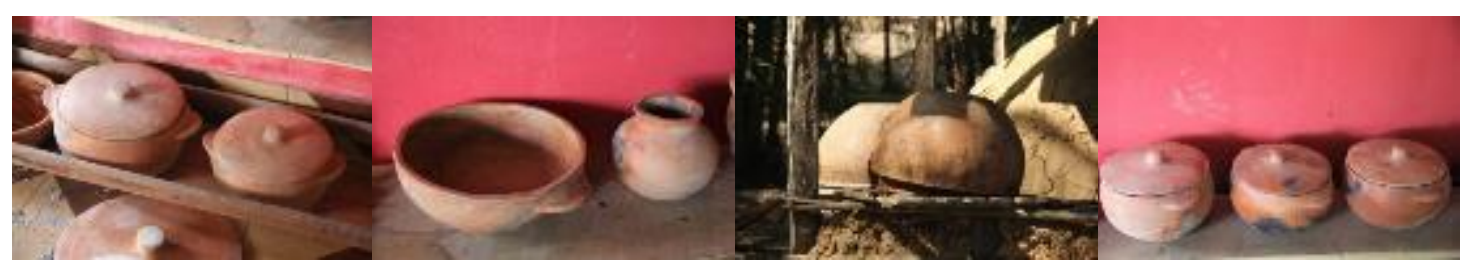

As peças são de aparência rústica e essa rusticidade não é entendida como simplicidade (FIGUEIREDO, 2009), pois é justamente essa característica que atribui ainda mais beleza e identidade às peças. Compreender a cadeia produtiva das louças, configurou-se como uma etapa fundamental na pesquisa para a efetivação de outras investigações científicas e para a concepção de elementos presentes, em e entre, cada etapa.

\section{A Cadeia Produtiva das Louças: reconhecendo elementos}

As observações realizadas em campo, apoiaram o entendimento sobre os processos produtivos das louças cerâmicas produzidas pelas artesãs, tanto às etapas de extração e conquista das cinzas de taquipé, quanto às etapas da argila vermelha, desde sua extração, passando pela incorporação das cinzas, até a finalização do processo produtivo, caracterizando assim a identificação da toda a cadeia produtiva.

O percurso que os materiais percorrem até serem transformados em cerâmicas utilitárias, compreende em dezoito etapas, que por vezes não seguem necessariamente uma ordem linear de produção. Sabe-se que a produção artesanal apresenta características diferentes de outros tipos de produção, principalmente quando o artesanato está inserido em contexto tradicional, onde existem outros fatores que transpassam a atividade produtiva.

A cadeia produtiva das louças apresenta uma combinação de processos entre a cadeia da cinza de taquipé e das louças. Primeiramente as etapas de produção das cinzas de taquipé são:

1. Seleção: na primeira etapa é selecionada a melhor árvore, cujo critério admitido consistem na escolha das maiores árvores, deixando os menores exemplares para o crescimento e, posterior futuras extrações;

2. Derrubada: após a seleção da árvore é realizada a sua derrubada em meio a floresta da amazônica maranhense;

3. Decomposição: a madeira precisa de um determinado período, aproximadamente de 6 meses a 1 ano, para que a decomposição natural possa ocorrer, facilitando a extração da casca;

4. Extração da casca: é nessa fase que as cascas são removidas do tronco da árvore com o auxílio de objetos afiados e cortantes. A extração das cascas é feita com cortes na parte superior do tronco caído ao chão, removendo as cascas à medida que estas se desprendem; 
5. Armazenamento: as cascas são depositadas em ambiente limpo e coberto para proteção contra agentes externos;

6. Queima da casca: a queima é realizada de forma simples, com a realização da combustão de todas as cascas;

7. Trituração: esta fase é realizada por um pilão manual, onde são colocadas as cascas já queimadas e ocorre desagregação das cascas em cinzas;

8. Peneiração: as peneiras utilizadas são geralmente peneira de cozinha ou peneiras maiores.

Finalizando a fase de peneira as cinzas estarão aptas para a incorporação à argila. Após as observações e exposição da cadeia produtiva da cinza de taquipé, apresenta-se as etapas produtivas das louças que compreendem em dez etapas. São elas:

1. Extração da Argila: retirada no período de estiagem dos campos alagado do rio Uru ${ }^{4}$, onde ocorre uma seleção a respeito da melhor argila a ser extraída. A segunda camada de argila é julgada de melhor qualidade para se produzir as louças, por conter menos matéria orgânica;

2. Secagem da argila: nessa fase a argila é exposta ao sol para que, com a insolação, possa secar;

3. Amolecimento: a argila é submergida em água por 24 horas, para melhor "controle" da umidade com a finalidade da conquista de uma consistência cremosa, apta para efetivação dos processos subsequentes;

4. Incorporação: a cinza é incorporada em uma "bola" de argila, ou seja, em uma porção de argila onde alguns punhados de cinza são misturados;

5. Modelagem: a técnica de modelagem utilizada é a serpentina. Essa técnica consiste primeiramente na, de posse da argila "temperada" ou incorporada com cinza de taquipé, produção de uma base circular com um vinco nas bordas para a acomodação das serpentinas (tiras de argila), uma sobre a outra, conformando a peça;

6. Acabamento: configura-se no processo de polimento da superfície das peças e correção de imperfeições leves. Nesta etapa utiliza-se algumas ferramentas facilitadoras, desenvolvidas pelo próprio saber-fazer;

7. Secagem das peças: as peças são deixadas em repouso por uma duração média de 12 a 24 horas, até que todo o excesso de água seja eliminado por meio da evaporação natural;

8. Esquente: o processo de esquente corresponde na continuação da eliminação de água que ainda existe em constituição à argila. As louças são dispostas em formato circular sobre uma base feita de tijolos cerâmicos, onde a lenha, geralmente bainhas ${ }^{5}$

\footnotetext{
${ }^{4}$ Rio que corta a região do povoado de Porto do Nascimento

5 Base ou região inferior da folha que envolve o caule da planta de forma parcial ou total (LORENZI et al., 2010).
} 
da folha da palmeira e o fruto do coco babaçu (Ataleia speciosa) ${ }^{6}$, são dispostas ao centro da organização, sendo então ateado fogo para a realização do procedimento;

9. Queima ou Sinterização: nesta etapa a disposição das louças, na base de tijolos cerâmicos muda, pois as louças são dispostas uma sobre a outra, formando uma espécie de pirâmide. Após a organização das peças, os materiais, utilizados para a realização da queima, são acomodados ao entorno destas, cobrindo-as uniformemente sem deixar espaços abertos e então novamente é ateado fogo na organização.

O processo de queima é realizado ao tempo e dura em média 1 hora.

10. Comercialização: após a finalização de toda a cadeia produtiva, destina-se as louças para a comercialização.

Portanto, a cadeia produtiva das louças cerâmicas das Anas, caracteriza-se por ser um dos poucos processos em que a cinza de taquipé é incorporada à argila vermelha para a produção artesanal tradicional de louças para uso direto à cocção. A incorporação do taquipé adere às peças a propriedade refratária, importante para a conservação do calor, propiciando o preparo de alimentos diretamente nas louças e não utilizá-las apenas como componente de função decorativa.

As informações adquiridas, por meio da observação, sobre a cadeia produtiva das louças, foram importantes para a definição dos elementos interpretados e para o desenvolvimento criativo da peça gráfica, com o intento de comunicar cada etapa produtiva de forma a facilitar a compreensão das informações e a passagem da interpretação do fazer artesanal.

\section{Interpretação gráfica de elementos representativos inseridos na cadeia produtiva das louças}

Para elaborar a representação gráfica da cadeia produtiva das Anas das louças partiu-se da observação das fotografias feitas em campo, associadas às informações obtidas durante a pesquisa, as quais permitiram compreender, de maneira ampliada, como se dão os processos para a confecção das peças cerâmicas, desde à seleção de matéria prima às etapas de comercialização. Após análises, foram escolhidas as fotografias que melhor correspondem às etapas da cinza de taquipé (Figura 3 ) e das louças (Figura 4).

6 Esses recursos são utilizados para as etapas de esquente e queima, devido a fácil oferta destes na mata da região. 
Figura 3: Fotografias do percurso produtivo das cinzas

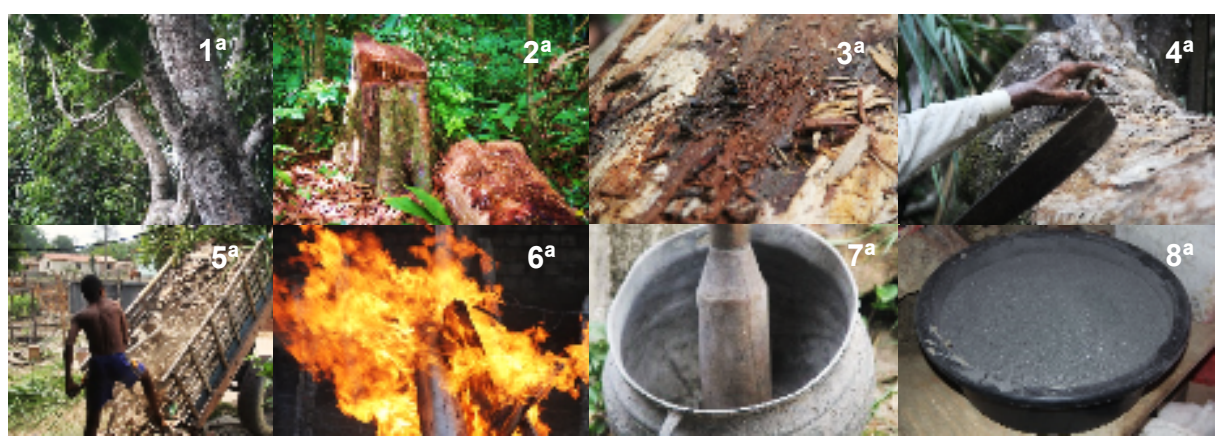

Figura 4: Fotografias do percurso produtivo das louças

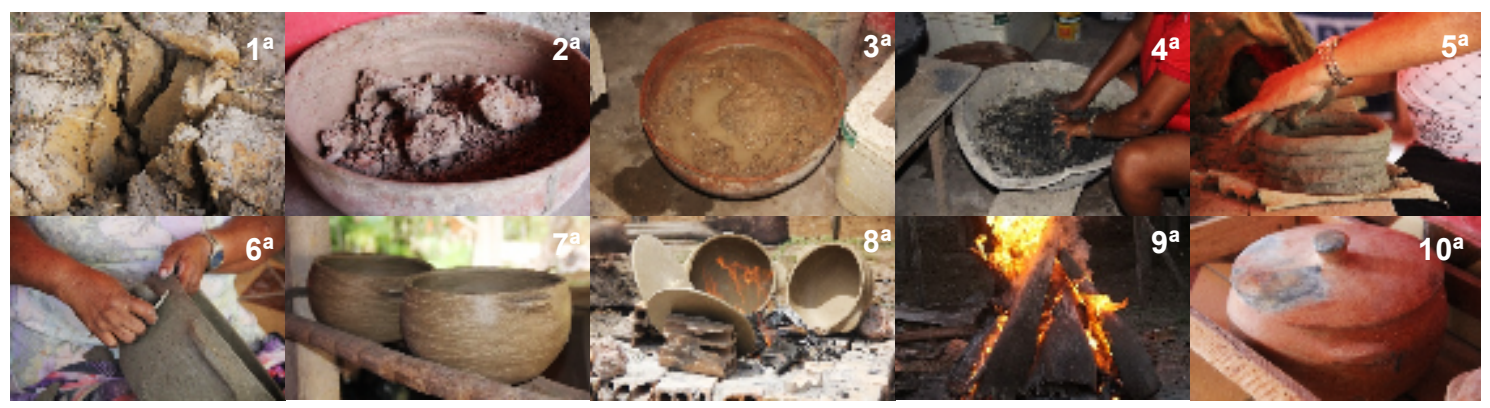

A partir das imagens fotográficas que registraram o fazer em campo, foi possível desenvolver ícones (Figura 5), para melhor representar as etapas de produção, de maneira clara e objetiva. Ao todo, foram desenvolvidos dezoito ícones, sendo 8 deles, referentes ao taquipé e os outros dez, referentes ao processo de produção e comercialização das louças. Cada ícone desenvolvido, buscou interpretar a atividade daquela etapa correspondente.

Figura 5: Iconografias gerais desenvolvidas

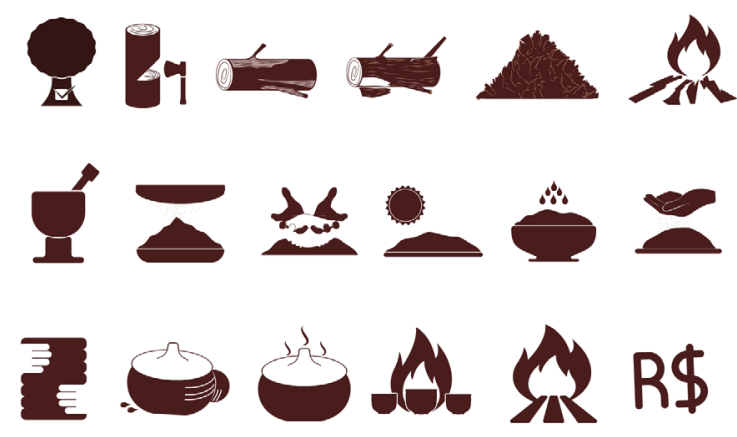

Sabendo que as etapas descritas, não ocorrem seguindo a mesma ordem linear, sendo algumas até realizadas por mais de uma vez, optou-se por desenvolver uma peça gráfica que comunicasse uma ordem sequencial das etapas por dependência, no sentido de que, uma etapa posterior, depende da anterior para acontecer, mesmo que, na prática, não seja seguida essa ordem. 
Portanto, desenvolveu-se um grid orgânico, no qual se disporia as etapas da cadeia produtiva, de acordo com a ordem sequencial mencionada (Figura 6). O grid foi interpretado no movimento da modelagem do tipo manual que as artesãs realizam para a conformação de suas peças. Logo, o movimento sinuoso das linhas por representarem uma ideia de sequência, assim como acontece nas serpentinas de argila, foram características percebidas e interpretadas para compor a base da peça gráfica.

Para ampliar a compreensão dos processos e aproximar os leitores da realidade das Anas, optou-se por utilizar tanto os ícones, quanto às fotografias para a apresentação das etapas, assim como a sua descrição por meio de palavras-chaves, sendo elas únicas ou compostas, dispostas acompanhando o movimento sinuoso das curvas.

Figura 6: Grid orgânico desenvolvido para peça gráfica

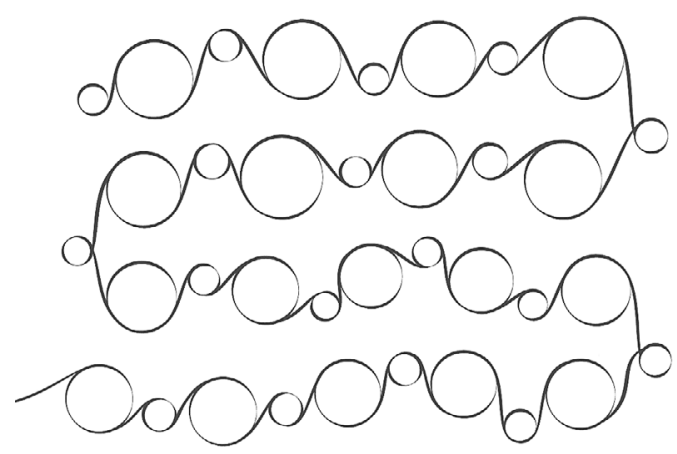

Para a paleta de cores, também foram utilizadas as fotografias do campo, como referência (Figura 7). Foi utilizado a cor laranja, como cor destaque, sendo ela a cor da louças cerâmicas prontas, as cores bege e rosa claro, que aparecem durante a extração da casca do taquipé, além das tonalidades marrom acinzentados, que são cores da argila, em diferentes fases do processo.

Figura 7: Paleta de cores escolhida

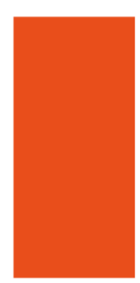

\#e94e1b

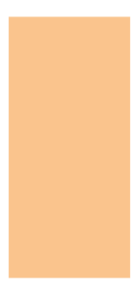

\#fac48d

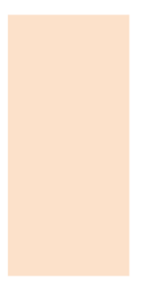

\#fce1cb

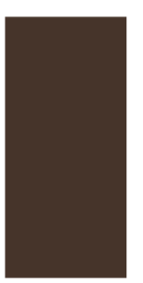

\#46332a

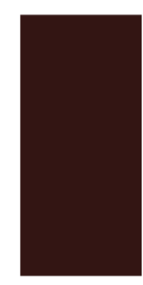

\#331514

A tipografia utilizada foi a Amaranth, selecionada por apresentar leves traços sinuosos, que harmonizam com a estética visual da peça gráfica como um todo, sem interferir na leiturabilidade e legibilidade dos textos inseridos (Figura 8). Para hierarquizar as informações, usou-se a fonte, em peso regular, nos tamanhos $62 \mathrm{pt}$, 32pt e 22pt, para o Título, subtítulo e palavras-chaves, respectivamente. 
Figura 8: Tipografia escolhida

1. Título-62pt

2. Subtítulo - 32 pt

3. Etapas - $22 \mathrm{pt}$

\section{II}

\section{Amaranth Regular}

\section{Amaranth Regular}

3. Amaranth Regular

A disposição dos elementos ocorreu seguindo o grid na etapa inicial do processo de desenvolvimento da peça gráfica, sendo as imagens utilizadas nos círculos em maior escala, os ícones, também em círculos, porém em e menor escala e as palavras-chave foram empregadas em curvas, seguindo a forma sinuosa das etapas representadas, as quais se referem (Figura 9). Dessa maneira, em perspectiva da vista superior pode-se identificar o contorno das panelas, produzidas pela artesãs, além do seguimento das etapas, que podem ir e vir, a depender das peculiaridades da produção de cada uma peça cerâmica.

Figura 9: Disposição das informações e dimensionamento entre ícone e fotografia

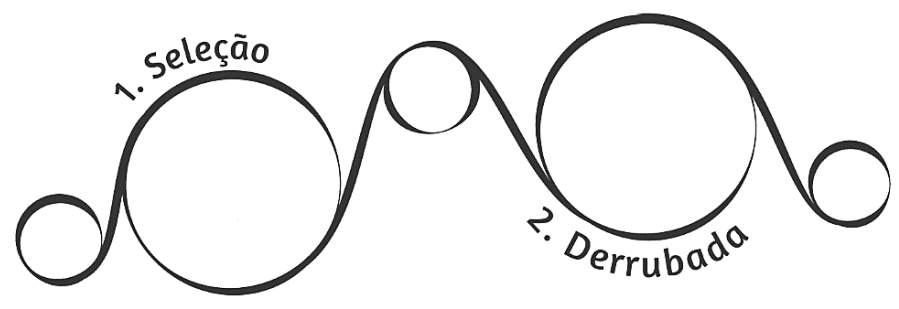

Buscou-se interpretar os principais elementos da cadeia produtiva das louças cerâmicas, a fim de comunicar de maneira objetiva e clara, bem como os elementos para o design da informação orientam, no desenvolvimento de uma peça gráfica que apresentasse uma proposta sólida e genuína, os processos artesanais do fazer louças pelas Anas.

\section{Resultado gráfico}

As observações, análises e interpretações da cadeia produtiva das louças cerâmicas, desde as etapas da cinza de taquipé, até a etapa de comercialização, foram compiladas e organizadas. Assim, após todo o percurso de pesquisas em campo, envolvimento com vários atores sociais e concretização da ação prática e criativa do artefato gráfico, apresenta-se a proposta final, utilizada para comunicar o fazer artesanal e tradicional das Anas das louças (Figura 10). 
Figura 10: Cadeia Produtiva das louças das Anas

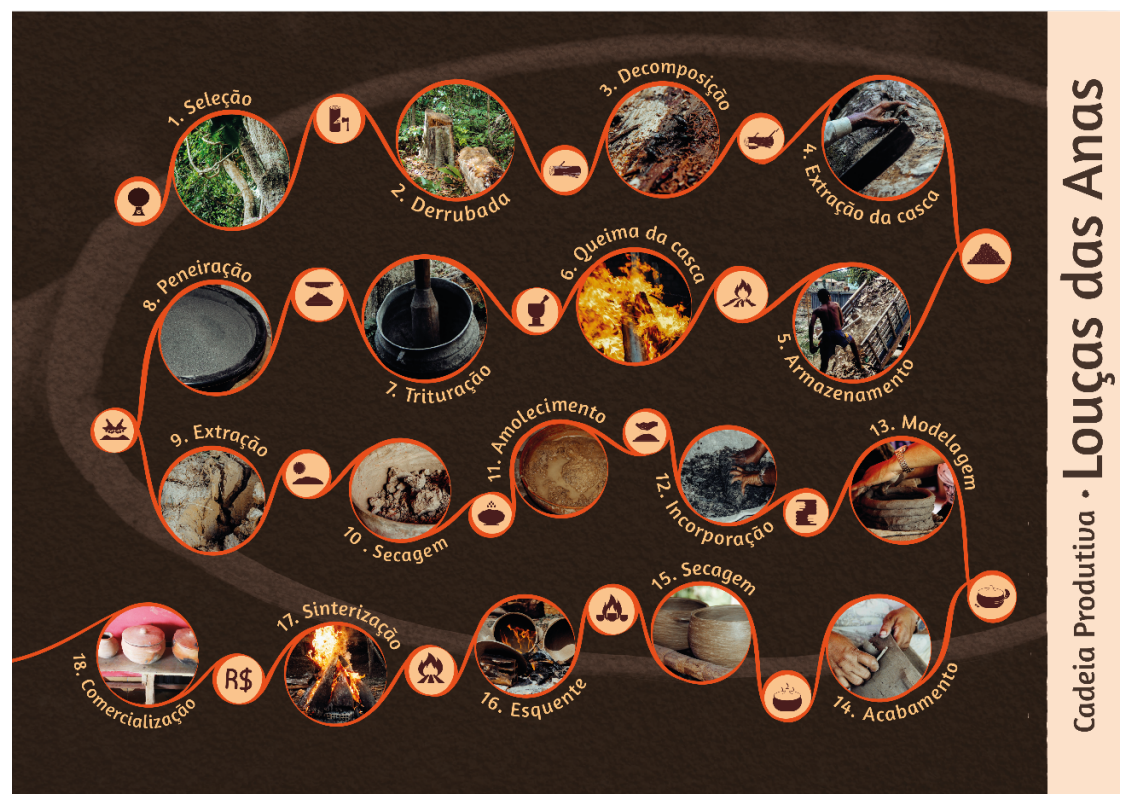

Destaca-se o papel do designer em meio ao processo de comunicação da tradição do fazer tradicional. As ações do designer deve pautar a valorização do conhecimento tradicional, advindo dos detentores de conhecimento tácito, pois uma das grandes características destes grupos, configura-se na transposição do conhecimento de geração em geração Neste caso, envolveu-se as práticas das artesãs Anas das louças, mulheres quilombolas do interior do estado do Maranhão, que carregam consigo técnicas peculiares e histórias por meio das louças de cerâmica e cinzas de taquipé.

\section{Conclusões}

A produção artesanal se destaca por ser um setor de grande importância para inúmeros indivíduos, espalhados pelos territórios. Muitos incentivos devem ser fomentados no intento da preservação das atividades proeminentes dessa cultura.

Cabe também ao design, o papel de agente facilitador no tocante a interlocução e comunicação dos conhecimentos tradicionais. Este artigo empregou sua atenção na comunicação da prática tradicional do fazer louças cerâmicas, contribuindo para um maior alcance da valorização desses fazeres.

Conclui-se que a cadeia produtiva percebida em campo, em sua completude, revela a importância da valorização da tradição, marcada pela atividade tradicional das artesãs, pois para além delas, outros atores sociais auxiliam no desenvolvimento dessas práticas, movimentando uma cadeia não somente de etapas produtivas, mais uma cadeia de experiências, vivências, comportamentos, na atmosfera que só existem em Porto do Nascimento, neste caso.

A relação com as Anas das Louças, evidenciou a riqueza cultural e histórica que esse grupo transporta, por meio de suas tradições e práticas, que são característicos do seu território. 
Desenvolver uma peça gráfica que comunique esse conhecimento tradicional, sem dúvida requer um outro posicionamento do designer, capaz de envolver-se com os atores sociais para promover a devida aproximação, mediação e conexão, correspondendo com o território.

O resultado da peça gráfica, denota a justa interpretação das informações e compreensão da força histórica que o fazer louças pelas Anas possuem, além de demonstrar que é possível a ação prática do design, sobretudo do design da informação, inserido em contextos tradicionais, atuando de forma a comunicar a tradição por meio do design. Portanto, o design também pode envolver as tecnologias, promovendo caminhos e instrumentos viabilizadores de comunicação de tradições, por meio de sua capacidade de transmitir a informação por caminhos imagéticos.

\section{Agradecimento}

Os autores agradecem à Coordenação de Aperfeiçoamento de Pessoal de Nível SuperiorCAPES, pelo fomento à pesquisa em mestrado acadêmico em design, por meio de bolsa, pelo Programa de Demanda Social. Destaca-se que o bolsista pesquisador (primeiro autor) que desenvolveu a dissertação em que se recorta este artigo, recebeu Menção Honrosa da CAPES como Pesquisa em Destaque 2020.

\section{Referências}

BERNARDES, Regina Helena Neto; MOTTA, João Antônio; BOTELHO, Ana Carolina Baker. 12383 - Comunidade quilombola: o conhecimento tradicional e seus reflexos na sustentabilidade de agroecossistemas na Amazônia Maranhense. Cadernos de Agroecologia, [S.I.], v. 6, n. 2, nov. 2011. ISSN 2236-7934. Disponível em:http://revistas.abaagroecologia.org.br/index.php/cad/article/view/12383. Acesso em: 12 ago 2019.

CARVALHO, Juliana; ARAGÃO, Isabella. Infografia: conceito e prática. Infodesign - Revista Brasileira de Design da Informação, [S.L.], v. 9, n. 3, p. 160-177, 7 maio 2013. Sociedade Brasileira de Design da Informacao. http://dx.doi.org/10.51358/id.v9i3.136.

DUARTE, Rosália. Pesquisa qualitativa: reflexões sobre o trabalho de campo. Cadernos de Pesquisa, [S.L.], n. 115, p. 139-154, mar. 2002. FapUNIFESP (SciELO). http://dx.doi.org/10.1590/s0100-15742002000100005.

FIGUEIREDO, Wilmara. Porto das Anas e das Louças. Rio de Janeiro: IPHAN, 2009. Disponível em: http://www.cnfcp.gov.br/pdf/CatalogoSAP/CNFCP_sap153.pdf. Acesso em: 15 ago. 2019.

KRUCKEN, Lia. Design e território: valorização de identidades e produtos locais. São Paulo: Studio Nobel, 2009.

MANZINI, E. Design, when everybody designs. An introduction to design for social innovation. London; Cambridge: The MIT Press, 2015. 241p. 
MIRANDA, Samuel da Silva. A tradição do punhado: avaliação da incorporação da cinza de taquipé (Triplaris sp.) em argila vermelha na produção artesanal. (Dissertação) - Mestrado em Design. Universidade Federal do Maranhão, São Luís, 2020.

NORONHA, Raquel; OLIVEIRA, Hamilton; ANDRADE, Camila (org.). A Cultura Afromaranhense através de imagens. São Luís: Edufma, 2009.

NORONHA, Raquel et al (Org.). Cirandas de Saberes: percursos cartográficos e práticas artesanais em Alcântara e na Baixada Maranhense. São Luís: Edufma, 2017.

OLIVEIRA, João Augusto Dias Barreira e; JORENTE, Maria José Vicentini. Design da informação e ciência da informação: uma aproximação possível. In: Encontro nacional de pesquisa em ciência da informação, 16., 2015, João Pessoa. Anais [...]. João Pessoa: Editora Ufpb, 2015. p. 01-20.

PATROCÍNIO, Gabriel. Design e os países em desenvolvimento: a dialética entre o design para a necessidade e o design para o desenvolvimento. In: PATROCÍNIO, Gabriel; Nunes, José Mauro (Org.). Design \& Desenvolvimento: 40 anos depois. São Paulo: Blucher, 2015. p. 264.

TUFTE, Edward R.. Envisioning Information. Connecticut: Graphics Press, 1998.

\section{Sobre os autores}

Samuel S. Miranda, Me., UFMA, Brasil <samueldsm@yahoo.com>

Denilson M. Santos, Dr., UFMA, Brasil <denilson.santos@ufma.br>

Ferdinan S. Sousa, Bel. UFMA, Brasil < ferdinansousa.16@gmail.com>

Elinaldo J. Mendes, Bel. ESTÁCIO, Brasil < elinaldomendesign@gmail.com> 